\title{
The Impact of Gloss Types on Reading Comprehension, Vocabulary Gain and Vocabulary Retention: A Comparative Study
}

\author{
Atefeh Elekaei (Corresponding author) \\ Department of English, Isfahan (Khorasgan) Branch, Islamic Azad University, Isfahan, Iran \\ E-mail: atefehelekaei@yahoo.com \\ Sajad Faramarzi \\ Department of English, Isfahan (Khorasgan) Branch, Islamic Azad University, Isfahan, Iran \\ E-mail: sajadfaramarzijj@gmail.com \\ Mansour Koosha \\ Department of English, Isfahan (Khorasgan) Branch, Islamic Azad University, Isfahan, Iran \\ E-mail: mansour.koosha@yahoo.com
}

Received: 16-01- 2015

Accepted: 27-03- 2015

Published: 01-09- 2015 doi:10.7575/aiac.ijalel.v.4n.5p.97

Advance Access Published: April 2015

URL: http://dx.doi.org/10.7575/aiac.ijalel.v.4n.5p.97

\begin{abstract}
The significance and impact of vocabulary learning in reading comprehension and L2 language learning are apparent to teachers, researchers and language learners. Moreover, glosses are found as one of the most effective strategies regarding vocabulary retention. Therefore, the present study attempted to investigate the effect of different types of glosses on reading comprehension, vocabulary gain and vocabulary retention. To this end, 140 Iranian EFL learners learning English were selected and were divided into four groups (footnote gloss group, interlinear gloss group, marginal gloss group, and glossary group). They were required to read a text and answer four reading comprehension questions. In addition, one immediate vocabulary post-test and one delayed vocabulary post-test were taken in order to investigate learners' vocabulary gain and vocabulary retention. In order to analyze the data, one one-way ANOVA and one MANOVA were run. The results of one-way ANOVA revealed that participants who received interlinear glosses significantly outperformed the other groups regarding comprehending the text. Moreover, the immediate vocabulary post-test was conducted immediately after reading test and the delayed post-test was administered after four weeks. The results of MANOVA indicated that the group which received interlinear glosses outperformed the other groups in both vocabulary gain and vocabulary retention. The present study has implications for teachers and learners. Teachers can find better methods to teach new reading passages as well as vocabulary items. Also, glosses help learners to have a better comprehension of difficult passages and they facilitate learning. Moreover, learners can enhance their vocabulary knowledge with the help of glosses.
\end{abstract}

Keywords: footnote gloss, interlinear gloss, marginal gloss, glossary, Iranian EFL learners, reading comprehension, vocabulary gain, vocabulary retention

\section{Introduction}

The significance and complexity of vocabulary learning in L2 language learning are obvious to teachers, researchers and language learners. Additionally, the relationship between vocabulary knowledge and reading comprehension is undeniable (Nagy, Herman and Anderson, 1985; Stoller and Grabe, 1993). In other words, L2 learners need to attain a certain level of vocabulary knowledge in order to comprehend the reading passages. One cannot comprehend reading texts without understanding the meaning of most words (Nagy, 1988). Therefore, many teachers have been trying to find ways and strategies in order to help students deal with unfamiliar words, enhance their knowledge of vocabulary and lead them to be more proficient in language learning. One of the techniques and strategies is including the use of glosses. Glosses can be used as one of the strategies in order to improve vocabulary knowledge and reading comprehension (Jacobs, Dufon and Hong, 1994). As Jacobs (1994) states, glossing "strengthens the bottom-up component of the reading process (p. 115).

Glosses are short definitions, explanations or translations of words or phrases which are unfamiliar to the readers (Richgels and Mateja, 1984). However, Roby (1999) believes that glosses are much more than explanations or translations of new words. Glosses are located interlinear (in-text), marginal (in margins), in footnote/endnote or in the appendix or glossary. 


\section{Literature Review}

There are two main types of vocabulary learning process: intentional and incidental (Huckin and Coady, 1999; Laufer and Hulstijn; 2001). In intentional vocabulary learning, learners enhance their vocabulary knowledge through conscious cognitive processing such as repetition, mnemonics and rehearsal. However, new words are added to learners' vocabulary with the help of reading a passage or listening to a speech in incidental vocabulary learning.

Gloss is one of the strategies which facilitate vocabulary learning and reading comprehension. Glosses can be located interlinear (in-text), in margins, in footnote/endnote or in the appendix or glossary. Interlinear (in-text) glosses are those types of glosses which are placed immediately after the new words. Marginal glosses are additional information in the margins of the same page or another page which play a mediator role between the given text and the learner. Footnote/endnote glosses are at the bottom of the page. As Zellwegar, Regli, Machinlay, and Cheng (2000) state "footnote placement in the bottom margin has the advantages of a predictable location, normal aspect ratio, and possible familiarity from footnotes on printed pages" (p. 250). Glossaries or the appendices include glosses at the end of the book, chapter or reading passage in an alphabetical list of terms.

Nation (1983) defines a gloss as a short definition. Nagata (1999) states four functions of gloss on vocabulary learning. First, marginal glosses are easier to use in contrast to dictionaries. Second, glosses include the notion of "consciousnessraising" and "input enhancement". Third, they support the "meaning-form connection" approach by relating words to meaning. Fourth, learners are encouraged to do lexical processing.

Moreover, Ko (2005) summarizes four advantages of glossing. First, gloss helps readers understand new words more precisely. Second, there is no need for L2 readers to look up the new words persistently. Third, readers relate prior knowledge to new knowledge with the help of gloss. Fourth, gloss gives readers greater autonomy.

Some studies have been done in order to investigate the effect of gloss on reading comprehension as well as vocabulary retention. Davis (1989) conducted a study in order to investigate whether marginal glosses promote comprehension of a text. To this end, seventy-one U.S. students who were in a French class were divided into three groups with three text conditions. The subjects of the first group were asked to read a short passage for fifteen minutes, then wrote what they could remember for ten minutes and finally reread the passage for five minutes. The subjects in the second situation were given a vocabulary guide, some notes and meaning of some new vocabularies before reading. So, they read the questions and notes for ten minutes, read the short passage for fifteen minutes and finally wrote what they could remember. The subjects of the third group were offered the same notes and meanings of the vocabularies in glossed form. They read the short passage for twenty-five minutes, and then wrote what they could remember. Based on the results, the text with glossed form helped students to outperform the other two groups significantly.

Johnson (1982) investigated vocabulary retention under four different conditions on reading comprehension. The four conditions were no help with vocabulary, reading the definitions of new words before reading, reading a passage with the new words in glossed form, and reading the new words before reading and reading the text with glosses. Seventy two ESL university students participated in the study. All the students took part in a cloze test, recalling the story in their L2 and recognizing exact sentence from the passage after reading. The results revealed that different types of vocabulary conditions did not significantly affect the comprehension. However, background knowledge of reading facilitated reading comprehension.

Jacobs, Dufon, and Fong (1994) conducted a study in order to compare the effect of L1 with L2 glosses on vocabulary learning as well as reading comprehension. Eighty five English-speaking students who were studying Spanish as a second language participated in the study. They read a Spanish text under three conditions: L1 (English) gloss, L2 (Spanish) gloss, and no gloss. Two vocabulary tests were given after reading the text: one immediately after the reading and the other four weeks later. Based on the results, no significant differences were found between groups taking L1 and L2 glosses. However, both L1 and L2 gloss groups were better than no gloss group.

Similarly, Chen (2002) examined L1 and L2 glosses with eighty five college students who were studying English as a second language in Taiwan. The students were divided into three groups: L1 (Chinese) gloss, L2 (English) gloss, and no gloss. The students were asked to read a 193-word English text with twenty new words in a glossed form. Supporting Jacobs, Dufon, and Fong (1994), no significant differences between L1 and L2 glosses were found.

Hulstijn, Hollander and Greidanus (1996) investigated the impact of glosses on incidental vocabulary learning. Three conditions were included: marginal gloss (L1), bilingual dictionary use, text-only (no glosses and no use of dictionary). It was found that marginal glosses (L1) were more effective than bilingual dictionary use or a text-only condition.

In a different study, Miyasako (2002) compared the effect of six groups of glosses including L2 (English) multiplechoice gloss, 11 (Japanese) multiple-choice gloss, L2 (English) single gloss, L1 (Japanese) single gloss, No gloss and control (no reading) on vocabulary learning. 187 Japanese high school students took part in the study. The students were required to read a 504-word text with twenty new words. Two vocabulary tests were taken after reading, one immediately after reading and the other 18 days later. Based on the results, although no significant differences between multiple-choice glosses and single glosses were found,L2 gloss groups(multiple-choice glosses or single glosses)answered significantly better than the L1 gloss groups (multiple-choice glosses or single glosses) regarding the immediate test.

Ko (2005) conducted another study in Korea. One hundred and six university students participated in the study. Twelve students were asked to think aloud, and the other ninety four participated in the main study. In the main study, 
participants were divided into three groups under three conditions: no gloss, Korean (L1) gloss and English (L2) gloss. The students were required to read the passage and answer the multiple-choice reading comprehension test. Based on the results, although only L2 gloss group performed the best in reading comprehension, the think-aloud group indicated that both L1 and L2 gloss groups read faster and also realized the passage better than no gloss group.

Alessi and Dwyer (2008) conducted another study with seventy six intermediate learners of Spanish in the United States and asked them to read a Spanish newspaper article under one of four different conditions. One group was given prereading activities including practice on the key vocabularies. The other group was given during-reading assistance including contextualized L1 translation in the form of hypertext glossing. The third group received both forms of assistance and the fourth group received neither forms of assistance. The results revealed that the group which received during-reading assistance performed better in reading comprehension than the group which received pre-reading assistance. In other words, interlinear glosses showed better results than pre-text glosses. In Alessi's and Dwyer's (2008) opinions, during-reading assistance is being "just-in-time".

Yanguas (2009) measured the effects of textual, pictorial, textual-pictorial glosses and no-gloss condition on vocabulary learning as well as reading comprehension. The students were divided into four groups under one of the four abovementioned conditions of glosses. The results revealed that participants in all kinds of glosses performed better than nogloss condition. Moreover, it was reported that no considerable differences were found among the groups regarding the production of the target words. Furthermore, textual-pictorial glosses were significantly the best group in reading comprehension.

Zarei and Hasani (2011) measured the effect of reading texts with interlinear, marginal, pre-text and post-text glossing conventions in eight groups. Four groups received the Persian equivalents of the target words in the form of glosses and four groups received intra-lingual L2 vocabulary glosses. Moreover, vocabulary gain and vocabulary retention were measured. Results showed that interlinear gloss was significantly better than post-text gloss in vocabulary retention. In addition, the differences among effects of interlinear, marginal, pre-text and post-text glossing conventions were not significant in the four groups which received intra-lingual glosses regarding vocabulary gain and vocabulary retention. Furthermore, the results of the pre-text and marginal conventions in inter-lingual glosses were considerably better than post-text group regarding vocabulary gain.

Moazzeni, bagheri, Sadeghi and Zamanian (2014) conducted a study in order to investigate the effect of single textual glosses, interactive glosses, multiple-choice glosses, multi-media glosses and multi-mode glosses on incidental vocabulary retention of Iranian EFL students. Results revealed that students who received different types of glosses had superior retention and the group which received glosses in the form of printed text definition with video clips outperformed the other groups.

Glosses have not largely studied until the last century. Moreover, little attention has been paid to the differences among footnote/endnote glosses, interlinear glosses, marginal glosses and appendix (glossary) glosses in vocabulary learning and reading comprehension. Therefore, the present study sought to investigate the differences among footnote/endnote glosses, interlinear glosses, marginal glosses and appendix (glossary) glosses in L2 vocabulary learning and reading comprehension in order to find the most effective type of glossing in both vocabulary learning as well as reading comprehension. Research questions of the present study are as follows:

1. Are there any significant differences among the effects of different types of glosses (footnote/endnote glosses, interlinear glosses, marginal glosses and appendix or glossary) on EFL students' reading comprehension?

2. Are there any significant differences among the effects of different types of glosses (footnote/endnote glosses, interlinear glosses, marginal glosses and appendix or glossary) on EFL students' vocabulary gain and retention in immediate and delayed tests?

\section{Methodology}

\subsection{Participants}

In order to collect data, 157 Iranian learners learning English at two language learning schools in Qazvin selected for the study. A Michigan Test of English Language Proficiency was administered to homogenize the students. The number of students reduced to 140 after taking the results of the proficiency test into account. The participants' age ranged from 17 to 27 and all of them were at intermediate level of proficiency.

\subsection{Instruments}

The following instruments were used in order to conduct the study:

1- The Michigan Test of English Language Proficiency

2- A vocabulary pre-test

3- A reading comprehension passage

4- An immediate vocabulary post-test

\section{5- A delayed vocabulary post-test}

First, The Michigan English Language Proficiency Test was administered in order to homogenize the students. Afterwards, a vocabulary pre-test including the target words of the reading passage was given to the students to make sure that participants did not know the target words. Then a reading passage from "Select Readings (Intermediate)" 
including 28 target words was given to the students under four conditions: footnote glosses, interlinear glosses, marginal glosses and glossary (at the end of the reading passage). Next, two vocabulary post-tests were administered: one immediate vocabulary post-test in order to measure the students' vocabulary gain and one delayed vocabulary posttest in order to measure students' vocabulary retention. These two vocabulary post-tests were in the form of multiplechoice test.

\subsection{Procedures}

First, The Michigan Test of English Language Proficiency was administered in order to make sure that the participants were at the same level of proficiency. 23 participants failed to take part in the rest of the study. Then, a vocabulary pretest was given to the students in order to make sure that the target words were unfamiliar to the participant. After that, students were divided into four groups and a reading passage from "Select Readings (Intermediate)" including 28 target words was given to them under four conditions: footnote glosses, interlinear glosses, marginal glosses and glossary (at the end of the reading passage). The participants were required to read the passage and answer four comprehension questions after reading. Then, the students received two vocabulary post-tests. One of them was administered immediately after reading the comprehension text which was immediate vocabulary post-test in order to investigate students' vocabulary gain and the other 4 weeks after reading the comprehension text which was delayed vocabulary post-test to measure students' vocabulary retention. Each of the post-tests included 28 questions related to 28 target words.

\subsection{Data Analysis}

In order to analyze the data and answer the research question number one, that is, the effects of different types of glosses (footnote/endnote glosses, interlinear glosses, marginal glosses and appendix or glossary) on EFL students' reading comprehension, one one-way ANOVA were run. Moreover, in order to answer the research question number two, that is, the effects of different types of glosses (footnote/endnote glosses, interlinear glosses, marginal glosses and appendix or glossary) on EFL students' vocabulary gain and retention in immediate and delayed tests, one MANOVA (multivariate analysis of variance) was used.

\section{Results}

The first research question sought to investigate the effects of different types of glosses (footnote/endnote glosses, interlinear glosses, marginal glosses and appendix or glossary) on EFL students' reading comprehension, one one-way ANOVA was conducted. Table 1 shows the descriptive and test statistics for the ANOVA on gloss types and reading comprehension.

Table 1. Descriptive and Test Statistics for the ANOVA on Gloss Types and Reading Comprehension

\begin{tabular}{lccccccc}
\hline & $\mathrm{N}$ & Mean & $\begin{array}{c}\text { Std. } \\
\text { Deviation }\end{array}$ & & $\begin{array}{c}95 \% \text { Confidence Interval for } \\
\text { Mean }\end{array}$ & Minimum & Maximum \\
\cline { 5 - 6 } & & & $\begin{array}{c}\text { Lower } \\
\text { Bound }\end{array}$ & $\begin{array}{c}\text { Upper } \\
\text { Bound }\end{array}$ & & \\
\hline Footnote Gloss & 35 & 15.91 & .853 & 15.62 & 16.21 & 15 & 17 \\
Interlinear Gloss & 35 & 21.77 & .808 & 21.49 & 22.05 & 21 & 23 \\
Marginal Gloss & 35 & 19.03 & .857 & 18.73 & 19.32 & 18 & 20 \\
Glossary & 35 & 12.89 & .796 & 12.61 & 13.16 & 12 & 14 \\
Total & 140 & 17.40 & 3.441 & 16.83 & 17.97 & 12 & 23 \\
\hline
\end{tabular}

As table 1 represents, interlinear gloss group has the highest mean (mean $=21.77)$, followed by the marginal gloss group $($ mean $=19.03)$, footnote gloss group $($ mean $=15.91)$ and glossary group $($ mean $=12.89)$. Therefore, participants in the interlinear gloss group significantly outperformed the other groups regarding reading comprehension. Moreover, F-value is statistically significant $(F=753.143, p<.01)$. Therefore, the differences among the four gloss types in reading comprehension are significant. In order to find differences among the four gloss types, the post hoc Scheffe test was utilized. Table 2 shows the results of gloss types on reading comprehension.

Table 2. Post Hoc Multiple Comparisons of Gloss Types on Reading Comprehension

\begin{tabular}{llcccc}
\hline (I) Gloss Types & $(\mathrm{J})$ Gloss Types & Mean Difference & Sig. & \multicolumn{2}{c}{$95 \%$ Confidence Interval } \\
\cline { 5 - 6 } & & $(\mathrm{I}-\mathrm{J})$ & & Lower Bound & Upper Bound \\
\hline Footnote Gloss & Interlinear Gloss & -5.857 & .000 & -6.42 & -5.30 \\
& Marginal Gloss & -3.114 & .000 & -3.68 & -2.55 \\
& Glossary & 3.029 & .000 & 2.47 & 3.59 \\
\hline Interlinear Gloss & Marginal Gloss & 2.743 & .000 & 2.18 & 3.30 \\
& Glossary & 8.886 & .000 & 8.32 & 9.45 \\
\hline Marginal Gloss & Glossary & 6.143 & .000 & 5.58 & 6.70 \\
\hline
\end{tabular}


As table 2 shows, there are significant differences among the four gloss groups. In other words, participants of the four gloss groups are significantly different in reading comprehension. Figure 1 represents the results the differences more conspicuously.

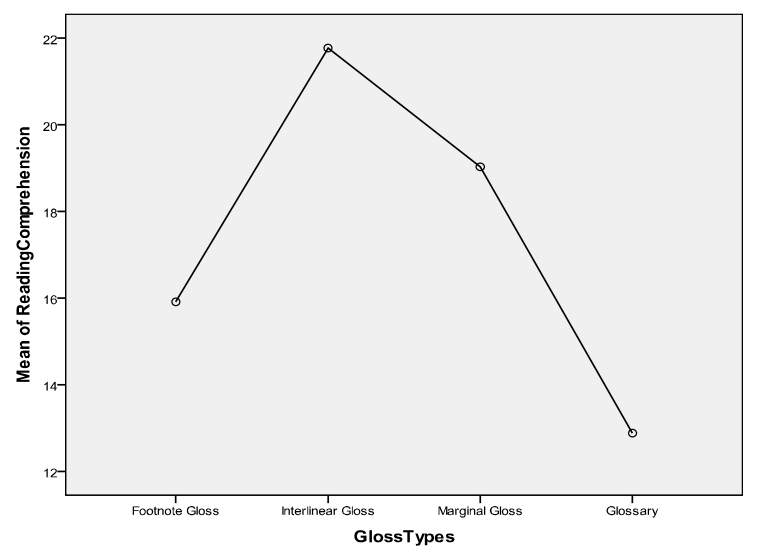

Figure 1. The Differences among Gloss Types and Reading Comprehension

The second research question in the present study sought to investigate the effects of different types of glosses (footnote/endnote glosses, interlinear glosses, marginal glosses and appendix or glossary) on EFL students' vocabulary gain and retention in immediate and delayed tests. Therefore, one MANOVA (multivariate analysis of variance) was used. Table 3 shows the results of MANOVA.

Table 3. Multivariate Test Results of the Effect of Gloss Types on Immediate and Delayed Vocabulary Post-Tests

\begin{tabular}{llrrrrrr}
\hline Source & Dependent Variable & $\begin{array}{c}\text { Type III Sum } \\
\text { of Squares }\end{array}$ & Df & $\begin{array}{c}\text { Mean } \\
\text { Square }\end{array}$ & F & $\begin{array}{c}\text { Sig. } \\
\text { Partial Eta } \\
\text { Squared }\end{array}$ \\
\hline Gloss Types & Immediate Vocabulary Post-Test & 1684.879 & 3 & 561.626 & 484.828 & .000 & .914 \\
& Delayed Vocabulary Post-Test & 2644.421 & 3 & 881.474 & 367.152 & .000 & .890 \\
\hline
\end{tabular}

As table 3 demonstrates, there are significant differences among gloss types in immediate vocabulary post-test $(\mathrm{F}=$ $484.828)$ and delayed vocabulary post-test $(\mathrm{F}=367.152)$. Moreover, as table 3 represents, gloss type account for $91 \%$ of the variance in immediate vocabulary post-test scores (partial eta squared $=.914$ ) and for $89 \%$ of the variance in delayed vocabulary post-test scores (partial eta squared $=.890$ ).

A post hoc Scheffe was run in order to find differences among the effect of four gloss types on immediate vocabulary post-test. Table 4 summarizes the results.

Table 4. Scheffe Post Hoc Results of the Effect of Gloss Types on Immediate Vocabulary Post-Test

\begin{tabular}{lccccc}
\hline Gloss Types & N & \multicolumn{5}{c}{ Subset } \\
\cline { 3 - 6 } & & 1 & 2 & 3 & 4 \\
\hline Glossary & 35 & 15.57 & & & \\
Footnote Gloss & 35 & & 16.94 & 20.40 & \\
Marginal Gloss & 35 & & & & 24.54 \\
Interlinear Gloss & 35 & & & &
\end{tabular}

Based on table 4 , interlinear gloss group $\left(\mathrm{X}^{\prime}=24.54\right)$ has significantly outperformed the other three gloss groups (footnote gloss group, marginal gloss group and glossary) on immediate vocabulary post-test. In other words, participants of the interlinear gloss group were considerably the best regarding vocabulary gain. Figure 2 shows the results more clearly.

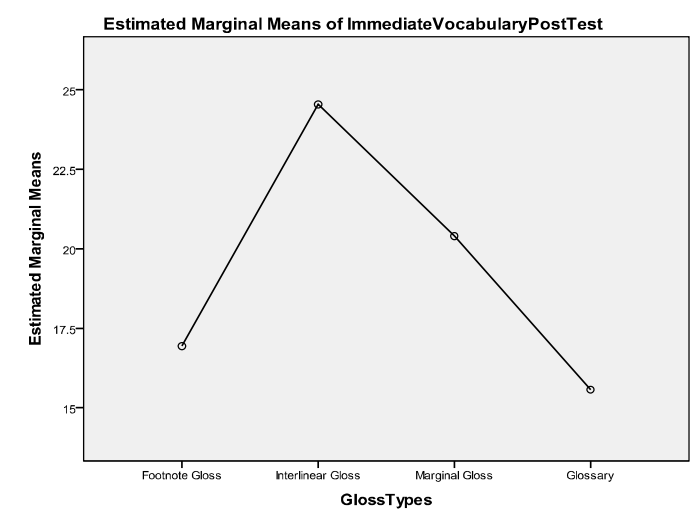

Figure 2. The Effect of Gloss Types on Immediate Vocabulary Post-Test 
In addition, in order to find differences among the four gloss types on delayed vocabulary post-test, a post hoc Scheffe was utilized. The results are summarized in Table 5.

Table 5. Scheffe Post Hoc Results of the Effect of Gloss Types on Delayed Vocabulary Post-Test

\begin{tabular}{lccccc}
\hline Gloss Types & N & \multicolumn{5}{c}{ Subset } \\
\cline { 3 - 5 } & & 1 & 2 & 3 & 4 \\
\hline Glossary & 35 & 10.09 & & & \\
Footnote Gloss & 35 & & 13.63 & & \\
Marginal Gloss & 35 & & & 16.20 & 22.00 \\
Interlinear Gloss & 35 & & & & \\
\hline
\end{tabular}

Based on table 5 , interlinear gloss group $\left(\mathrm{X}^{\prime}=22.00\right)$ has significantly outperformed the other three gloss groups (footnote gloss group, marginal gloss group and glossary) on delayed vocabulary post-test. In other words, participants of the interlinear gloss group were considerably the best regarding vocabulary retention. Figure 3 shows the results more clearly.

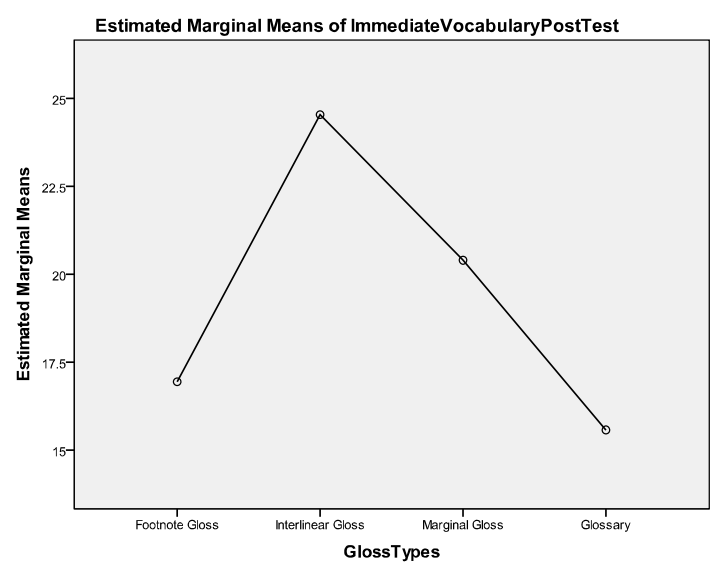

\section{Discussion}

Figure 3. The Effect of Gloss Types on Delayed Vocabulary Post-Test

The first research question investigated the effects of different types of glosses (footnote/endnote glosses, interlinear glosses, marginal glosses and appendix or glossary) on EFL students' reading comprehension. Based on the results, the group of students under the condition of interlinear glosses significantly comprehend the reading text better that the other groups. There are some reasons to support this finding. The interlinear glosses were located immediately after the new words. As a result, students primarily could concentrate on the glosses immediately after observing them, understand the meanings and continue reading the text. Additionally, the students did not waste their time searching and finding the glosses related to the new words in margins, footnotes or glossaries.

The results of the present study support Alessi's and Dwyer's (2008) study in which it demonstrated that interlinear glosses had better results than pre-text glosses. In Alessi's and Dwyer's (2008) opinions, during-reading assistance is being "just-in-time". At the same time, the results of the present study contradict those of Johnson (1982) in which different types of vocabulary conditions did not significantly affect the comprehension. This study is different from Jacobs, Dufon, and Fong (1994) and Chen (2002) who found no significant differences between two different types of glosses immediately after the reading and four weeks later. Moreover, the findings of the present study are different from those of Hulstijn, Hollander and Greidanus (1996) which showed that marginal glosses (L1) were more effective than bilingual dictionary use or a text-only condition.

Another outcome of the present study is that interlinear gloss group outperformed the other groups (the footnote gloss group, the marginal gloss group, and the glossary gloss group) in both immediate and delayed vocabulary post-tests (vocabulary gain and vocabulary retention, respectively). This result is compatible with those of Zarei and Hasani (2011) that interlinear glosses were significantly better than post-text gloss in vocabulary retention.

At the same time, the findings of the present study are in contrast with some previous studies (Davis, 1989; Yanguas, 2009; Zarei and Hasani, 2011; Moazzeni et al., 2014). Similarly, the results of this study are different from Davis's (1989) findings that revealed that the group which received pre-text and marginal glosses performed significantly. Moreover, the findings of the present study contradict those of Yanguas (2009) in which no significant differences were found in among various types of glossing regarding vocabulary production. Also, the findings of this study are different from those of Zarei and Hasani (2011). They found that marginal glosses were significantly better than post-text glosses in vocabulary gain. Furthermore, the findings of the present study are different from Moazzeni, bagheri, Sadeghi and Zamanian's (2014) findings. They showed that students who received different types of glosses had superior retention and the group which received glosses in the form of printed text definition with video clips outperformed the other groups. 


\section{Conclusion}

The present study aimed at investigating the effects of different types of glosses on EFL students' reading comprehension, vocabulary gain and retention. Therefore, the first research question measured footnote/endnote glosses, interlinear glosses, marginal glosses and appendix or glossary on EFL students' reading comprehension. The results of one-way ANOVA revealed that participants who received interlinear glosses significantly outperformed the other groups regarding comprehending the text. The second research question investigated the effects of footnote/endnote glosses, interlinear glosses, marginal glosses and appendix or glossary on EFL students' vocabulary gain and vocabulary retention. To this end, one immediate vocabulary post-test was conducted immediately after reading test and one delayed post-test was administered after four weeks. The results indicated that the group which received interlinear glosses outperformed the other groups in both vocabulary gain and vocabulary retention.

The present study has implications for teachers as well as learners. Teachers can find better ways to teach new reading passages and vocabulary items. Also, glosses assist learners to have a better understanding of difficult passages and they facilitate learning. Moreover, learners can enhance their vocabulary knowledge with the help of glosses.

\section{References}

Alessi, S. \& Dwyer, A. (2008). Vocabulary assistance before and during reading. Reading in a Foreign Language, 20 (2), 246-263.

Chen, H. (2002). Investigating the effect of L1 and L2 glosses on foreign language reading comprehension and vocabulary retention. Paper presented at the Annual Meeting of the Computer-Assisted Language Instruction Consortium, Davis, CA.

Davis, N. (1989). Facilitating effects of marginal glosses on foreign language reading. The Modern Language Journal, 73 (1), 41-48.

Huckin, T. \&Coady, J. (1999). Incidental vocabulary acquisition in a second language: A review. Studies in Second Language Acquisition, 21(2), 181-193.

Hulstijn, J. H., Hollander, M. \&Greidanus, T. (1996). Incidental vocabulary learning by advanced foreign language students: The influence of marginal glosses, dictionary use, and reoccurrence of unknown words. The Modern Language Journal, 80 (3), 327-339.

Jacobs, G. M. (1994). What lurks in the margin: Use of vocabulary glosses as a strategy in second language reading.Issues in Applied Linguistics, 5(1), 115-137.

Jacobs, G. M., Dufon, P. \& Fong, C. H. (1994). L1 and L2 vocabulary glosses in L2 reading passages: Their effectiveness for increasing comprehension and vocabulary knowledge. Journal of Research in Reading, 17 (1), 19-28.

Johnson, P. (1982). Effects on reading comprehension of building background knowledge. TESOL QUARTERLY, 16 (4), 503-516.

Ko, M. H. (2005). Glosses, comprehension, and strategy use. Reading in a Foreign Language, 17 (2), 125-143.

Laufer, B. \&Hulstijn, J. H. (2001). Incidental vocabulary acquisition in a second language: The construct of taskinduced involvement. Applied Linguistics, 22(1), 1-26.

Miyasako, N. (2002). Does text-glossing have any effects on incidental vocabulary learning through reading for Japanese senior high school students? Language Education \& Technology, 39, 1-20.

Moazzeni, Zh., Bagheri, M. S., Sadighi, F. \& Zamanian, M. (2014). The effect of different gloss types on incidental vocabulary retention of Iranian EFL students. International Journal of Language Learning and Applied Linguistics World, 5 (2), 396-415.

Nagata, N. (1999). The effectiveness of computer-assisted interactive glosses. Foreign Language Annals, 32 (4), 469479 .

Nagy, W. E. (1988). Teaching vocabulary to improve reading comprehension. Newark, DE: International Reading Association.

Nagy, W. E., Herman, P. A. \& Anderson, R. C. (1985). Learning words from context. Reading Research Quarterly, 20(2), 233-253.

Nation, I. S. P. (1983). Teaching and learning vocabulary. Wellington: English Language Institute, Victoria University. Richgels, D. J. \&Mateja, J. A. (1984). Gloss II: Integrating content and process for independence. Journal of Reading, 27(5), 424-431.

Roby, W. B. (1999). What's in a gloss? Language Learning \& Technology, 2(2), 94-101.

Stoller, F. L. \&Grabe, W. (1993). Implications for L2 vocabulary acquisition and instruction from L1 vocabulary research. In T. Huckin, M. Haynes, \& J. Coady (Eds.), Second language reading and vocabulary learning (pp. 24-45). Norwood, NJ: Ablex Publishing.

Yanguas, I. (2009). Multimedia Glosses and their effect on L2 text comprehension and vocabulary learning. Language Learning \& Technology, 13(2), 48-67.

Zarei, A. A. \&Hasani, S. (2011). The effect of glossing conventions on L2 vocabulary recognition and production. The Journal of Teaching Language Skills, 3(2), 209-233.

Zellwegar, P. T., Regli, S. H., Machinlay, J. D. \& Cheng, B. W. (2000). The impact of fluid documents on reading and browsing: An observational study. CHI Letters, 2(1), 249-256. 